\title{
Estimation of larval duration in Anguilla spp., based on cohort analysis, otolith microstructure, and Lagrangian simulations
}

\author{
Kei Zenimoto ${ }^{1, *}$, Yoshikazu Sasai ${ }^{2}$, Hideharu Sasaki ${ }^{3}$, Shingo Kimura ${ }^{1}$ \\ ${ }^{1}$ Atmosphere and Ocean Research Institute/Graduate School of Frontier Sciences, University of Tokyo, 5-1-5, Kashiwanoha, \\ Kashiwa, Chiba 277-8564, Japan \\ ${ }^{2}$ Research Institute for Global Change, Japan Agency for Marine-Earth Science and Technology, 3173-25 Showa-machi, \\ 15 Kanagawa-ku, Yokohama, Kanagawa 236-0001, Japan \\ ${ }^{3}$ Earth Simulator Center, Japan Agency for Marine-Earth Science and Technology, 3173-25 Showa-machi,15 Kanagawa-ku, \\ Yokohama, Kanagawa 236-0001, Japan
}

\begin{abstract}
The larval stage duration of fish species can be estimated by cohort analysis, otolith microstructure analysis, and Lagrangian simulations. A number of previous studies have indicated that age estimates based on otolith analysis may be underestimated in anguillid species, because increment deposition decreases at low ambient temperature. We used Lagrangian simulations to estimate the mean larval duration of the European eel Anguilla anguilla and the Japanese eel A. japonica and compared our estimates to the number of otolith increments, which is influenced by ambient temperature. Larvae are transported from the spawning grounds to recruitment areas, experiencing temperatures of 13.0 to $22.5^{\circ} \mathrm{C}$ in $A$. anguilla and 20.0 to $27.0^{\circ} \mathrm{C}$ in $A$. japonica. The simulated larval durations can be used to calculate the number of otolith increments, once corrected for the effect of ambient temperature of 313 and $208 \mathrm{~d}$ for A. anguilla and A. japonica, respectively. These estimates agreed well with those derived from otolith microstructure analyses in both species. We conclude that larval duration based exclusively on otolith microstructure analysis can be underestimated. The duration of the larval stage of A. anguilla and A. japonica confirmed by otolith increment counts corrected for the effect of ambient temperature, is approximately 2 yr and 7 mo, respectively.
\end{abstract}

KEY WORDS: Anguilla anguilla $\cdot$ European eel $\cdot$ Anguilla japonica $\cdot$ Japanese eel $\cdot$ Lagrangian simulation $\cdot$ Larval duration $\cdot$ Ambient temperature $\cdot$ Otolith

\section{INTRODUCTION}

The European eel Anguilla anguilla and the Japanese eel $A$. japonica are well known catadromous fish species. Both species spawn far offshore in the pelagic habitat (the Sargasso Sea for A. anguilla and west of Mariana Island for A. japonica), and their larvae are passively transported by ocean currents to coastal waters near their recruitment areas. Before their arrival in coastal waters, the larvae metamorphose into glass eels and then recruit to estuaries. In the larval phase, they undergo long distance migra- tions (>6000 km for A. anguilla, 2000 to $3000 \mathrm{~km}$ for A. japonica).

Stocks of both species are now considered to be collapsed because their recruitment has continuously declined over a long period of time (Casselman \& Cairns 2003, ICES 2006). Recruitment of Anguilla anguilla has significantly declined since the end of the 1970s (ICES 2006). Because of this decline, A. anguilla was listed in Appendix II of the Convention on International Trade in Endangered Species of Wild Fauna and Flora (CITES) in June 2007. Likewise, recruitment of $A$. japonica has also declined in 
most habitats since the late 1970s (Tatsukawa 2003, Miller et al. 2009).

The decline of both species has been caused by several factors, including overfishing (Dekker 2003), habitat degradation and loss by human activity such as constructions of dams and weirs (Feunteun 2002, Dekker 2003, Laffaille et al. 2007), and fluctuations in oceanic conditions (Knights 2003, Kimura \& Tsukamoto 2006, Friedland et al. 2007, Kim et al. 2007, Bonhommeau et al. 2008a,b, Zenimoto et al. 2009). For most marine species, changes in survival rate during their early life stages have a potentially significant impact on their stocks. Because both eel species have a protracted oceanic larval phase, the oceanic conditions and their fluctuation have a potentially considerable influence on these stocks.

Although information on the early life history of each species (e.g. spawning time and larval duration) has been estimated by otolith microstructure analysis, some previous studies have questioned or rejected these analysis methods (McCleave 2008, Bonhommeau et al. 2010). By back-calculation based on otolith analysis, the timing of spawnings of Anguilla anguilla, A. japonica, and the American eel A. rostrata were estimated to be much later than those inferred by the presence of hatching larvae in the spawning areas (McCleave 2008). This suggested that estimating the age of the glass eels based exclusively on otolith microstructure analysis was not reliable. In addition, Bonhommeau et al. (2009a) investigated the duration of migration for A. anguilla by Lagrangian simulation. This work also concluded that age determination by otolith microstructure analysis had been underestimated because larvae could not migrate from the ocean spawning grounds to the coast within the estimated timescales, even if they were capable of active directed swimming.

One of the reasons for underestimating migration duration is that the formation of daily otolith increments depends on ambient temperature. Fukuda et al. (2009) reported that otolith growth and daily increment deposition of Anguilla japonica glass eels and elvers decreased at temperatures below $15^{\circ} \mathrm{C}$ and ceased at temperatures below $10^{\circ} \mathrm{C}$. Therefore, during the larval migration phase, the increment formation speed and otolith growth rates could decrease if they experienced low ambient temperature.

In this study, we tested the hypothesis of underestimation in larval migration duration by otolith microstructure analysis. For this purpose, we used Lagrangian numerical simulations of larval transport and model temperature data to estimate mean larval duration and the ambient temperature regime expe- rienced by Anguilla anguilla and A. japonica. This study aims to expand on previous knowledge of larval duration, such as the work of Kettle \& Haines (2006) and Bonhommeau et al. (2009b) for A. anguilla and of Kimura et al. (1999) and Kim et al. (2007) for A. japonica. The numbers of increments formed during the larval stage at certain ambient temperatures were estimated based on Fukuda et al. (2009). Estimated larval migration duration and otolith increment counts were compared between the numerical simulations and otolith microstructure analysis.

\section{MATERIALS AND METHODS}

\section{Hydrodynamic model}

The Ocean General Circulation Model for the Earth Simulator (OFES, Masumoto et al. 2004) was used to simulate 3-dimensional oceanic fields in the world ocean. The OFES model was driven by realistic atmospheric forcing including temporal and spatial variability. The horizontal grid size was $1 / 10^{\circ}$ in the zonal and meridional directions with 54 vertical levels of thickness ranging from 5 to $330 \mathrm{~m}$ (Masumoto et al. 2004).

A hindcast integration performed by this model for 1950 to 2004 (Sasaki et al. 2008) successfully reproduced the decadal upper layer variability in the western North Pacific (Nonaka et al. 2006, Taguchi et al. 2007). The typical sea surface temperature fluctuation pattern in the North Pacific, as represented by empirical orthogonal functions (EOF) known as the Pacific decadal oscillation (Mantua et al. 1997), is well reproduced by the model. In the North Atlantic, OFES also reproduced fine-scale flow fields including mesoscale eddies (Nakamura \& Kagimoto 2006, Masumoto 2010) and thermal structures (Doi et al. 2009). Because of their high resolution and reproducibility, OFES outputs have been used for the particle-tracking calculations to estimate larval transport of the Japanese anchovy Engraulis japonicus, sardine Sardinops melanostictus (Itoh et al. 2009), and Anguilla japonica (Kim et al. 2007, Zenimoto et al. 2009), and also to understand the temperature environment experienced by Pacific bluefin tuna Thunnus orientalis (Kitagawa et al. 2009).

\section{Simulation design}

Egg and larval dispersal was simulated by the particle-tracking model assuming passive particles, with 
no horizontal swimming behavior and mortality. Horizontal current velocities of the OFES model were used for larval transport simulation. The governing equations for the horizontal movement of particles were as follows:

$$
\begin{aligned}
& x_{t+1}=x_{t}+U \Delta t+\mathrm{R}_{\mathrm{x}} \times 2 \mathrm{~K}_{\mathrm{h}} \Delta t^{-1 / 2} \\
& y_{t+1}=y_{t}+V \Delta t+\mathrm{R}_{\mathrm{y}} \times 2 \mathrm{~K}_{\mathrm{h}} \Delta t^{-1 / 2}
\end{aligned}
$$

$x_{t}$ and $y_{t}$ are the position of a particle at time step $t$. $U$ and $V$ are the eastward and northward velocity components, respectively. $R_{x}$ and $R_{y}$ are normal random numbers with a standard deviation of $1 . K_{h}$ is the horizontal eddy diffusivity coefficient $\left(10^{2} \mathrm{~m}^{2} \mathrm{~s}^{-1}\right)$. Particle positions were updated every $20 \mathrm{~min}(\Delta t)$.

\section{Lagrangian simulations and analysis}

One thousand particles were released every $0.5^{\circ}$ and $0.2^{\circ}$ horizontally over the assumed spawning area where most small larvae of Anguilla anguilla (McCleave 1993; Fig. 1a) and A. japonica (Tsukamoto 2006; Fig. 1b) were observed. Spawning time, computation period, and range of diurnal vertical migration parameters are summarized in Table 1. To avoid a biased outcome resulting from the prevailing climate phase, we performed simulations for a low, regular, and high winter North Atlantic oscillation index (NAOI) and likewise for the Southern oscillation index (SOI) (Table 1). The winter NAOI (Hurrell 1995) and the SOI are well known as large-scale and integrative indices in the North Atlantic and North Pacific, respectively. Particles were released at model dates 1 February, 1 March, and 1 April for A. anguilla (McCleave \& Kleckner 1987, McCleave 2008) and 1 May, 1 June, and 1 July for A. japonica (Tabeta et al. 1987, Tsukamoto 1990, McCleave 2008), coincident with peak spawning for both species (Table 1). The vertical position of particles was designed to mimic the diurnal vertical migration of the larvae. The early life stage of both species from hatching to the lepto-
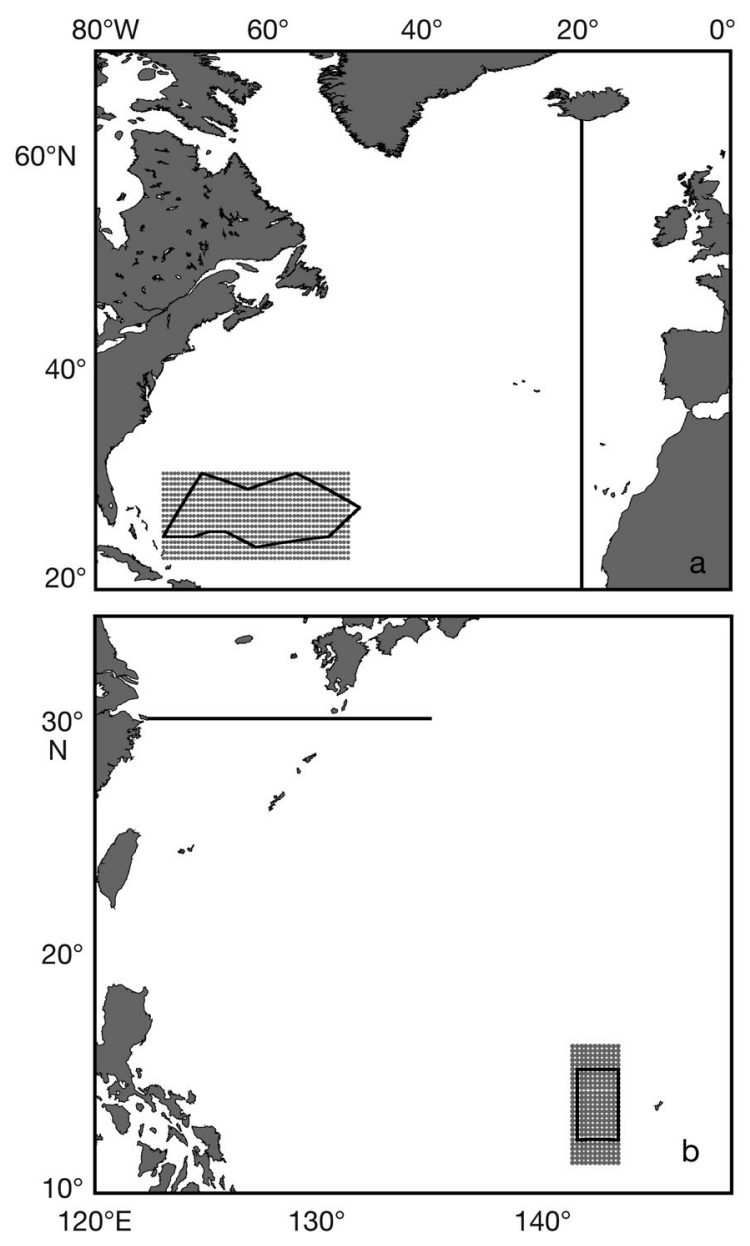

Fig. 1. (a) Location of the European eel spawning area (polygon; data from McCleave 1993), initial positions for the Lagrangian simulations (fine grid behind polygon, each grid square $0.5^{\circ} \times 0.5^{\circ}$ ), and the 'arrival line' along $20^{\circ} \mathrm{W}$. (b) Location of the Japanese eel spawning area (rectangle; data from Tsukamoto 2006), initial positions for the Lagrangian simulations (i.e. each grid square $0.2^{\circ} \times 0.2^{\circ}$ ), and the 'arrival line' along $30^{\circ} \mathrm{N}$

cephalus form occurs in the upper epipelagic to upper mesopelagic layers (Castonguay \& McCleave 1987, Otake et al. 1998). Atlantic Anguilla species including $A$. anguilla $<5 \mathrm{~mm}$ in total length (TL) per-

\begin{tabular}{|c|c|c|c|c|c|}
\hline \multirow{2}{*}{ Release position } & \multicolumn{2}{|c|}{ - Release timing } & \multirow{2}{*}{$\begin{array}{l}\text { Computation } \\
\text { period (yr) }\end{array}$} & \multicolumn{2}{|c|}{ Diurnal vertical migration (m) } \\
\hline & Year & Month & & Day & Night \\
\hline \multicolumn{6}{|l|}{ A. anguilla } \\
\hline $50^{\circ} \mathrm{W}-74^{\circ} \mathrm{W}, 20^{\circ} \mathrm{N}-30^{\circ} \mathrm{N}$ & $\begin{array}{l}1964-1967(\text { NAOI }<0) \\
1974-1977(\text { NAOI }=0) \\
1990-1993(\text { NAOI }>0)\end{array}$ & Feb, Mar, Apr & 4 & 300 & 50 \\
\hline \multicolumn{6}{|l|}{ A. japonica } \\
\hline $141^{\circ} \mathrm{E}-143^{\circ} \mathrm{E}, 11^{\circ} \mathrm{N}-16^{\circ} \mathrm{N}$ & $\begin{array}{c}1991-2006 \\
\text { (including all SOI phases) }\end{array}$ & May, Jun, Jul & 1 & 150 & 50 \\
\hline
\end{tabular}

Table 1. Summary of conditions for the Lagrangian study 
form a diurnal vertical migration (Castonguay \& McCleave 1987). Larvae of $A$. anguilla are distributed at depths of 100 to $150 \mathrm{~m}$ during the day and 50 to $100 \mathrm{~m}$ at night until they reach $20 \mathrm{~mm}$ TL. Larvae $>20 \mathrm{~mm}$ TL are distributed at depths of 125 to $275 \mathrm{~m}$ during the day and 30 to $70 \mathrm{~m}$ at night (Castonguay \& McCleave 1987). Larvae of A. japonica from 10 to $20 \mathrm{~mm}$ $\mathrm{TL}$ are distributed at 100 to $250 \mathrm{~m}$ during the day and 50 to $100 \mathrm{~m}$ at night (Otake et al. 1998). In this study, all larvae were allowed to migrate vertically throughout the simulations as described below. Based on observational data, the depth of the larvae was set to $300 \mathrm{~m}$ during the day (06:00 to $18: 00 \mathrm{~h}$ local time) and $50 \mathrm{~m}$ at night (18:00 to 06:00 h) for $A$. anguilla, and $150 \mathrm{~m}$ during the day and $50 \mathrm{~m}$ at night for A. japonica (Table 1). Particles were allowed to drift over $4 \mathrm{yr}$ for $A$. anguilla and $1 \mathrm{yr}$ for A. japonica, which is long enough to encompass the maximum larval duration.

In the diurnal vertical migration depth range, temperature decreases with depth. Therefore, larvae of both species would experience temperature changes between the uppermost (maximum temperature) and lowest layers (minimum temperature) in the migration depth range. To determine ambient temperature values experienced by virtual larvae, the uppermost and lowest layer temperatures at each particle position were determined by horizontally interpolating OFES output temperature data.

\section{Analysis}

Definition of transport success and larval duration. Output files of Lagrangian simulations included the position (longitude, latitude, depth) and time for each particle. We established 'arrival lines' at longitude $20^{\circ} \mathrm{W}$ and latitude $30^{\circ} \mathrm{N}$ based on previous studies for Anguilla anguilla (Bonhommeau et al. 2009a) and A. japonica (Kim et al. 2007, Zenimoto et al. 2009), respectively (Fig. 1a,b). In this study, transport success and larval duration were defined as crossing these arrival lines.

Application of natural mortality to estimates of larval duration. To provide accurate estimates of larval duration, natural mortality has to be accounted for in Lagrangian simulations. In this study, Lagrangian experiments were performed without any natural mortality, and then we applied natural mortality as follows. Net numbers of virtual larvae with larval duration $t, R(t)$, are estimated as

$$
R(t)=N(t) \mathrm{e}^{-M t}
$$

where $N$ denotes the number of successfully transported larvae without applying natural mortality, and $M$ is the natural mortality coefficient. In a previous study, $M$ for Anguilla anguilla was estimated to be 3.8 (Bonhommeau et al. 2009b). In this study, $M$ was set to be 1.0 to 4.0 for $A$. anguilla and 1.0 to 5.0 for $A$. japonica.

Estimation of increment numbers of virtual larvae using ambient temperature. The number of identifiable increments depends on ambient temperature for glass eels and elvers of Anguilla japonica (Fukuda et al. 2009). Thus, otolith microstructure analysis could underestimate larval duration. To test the temperature dependence of increment formation, we corrected the increment count derived from the Lagrangian simulations by applying the temperature and increment deposition relationship proposed by Fukuda et al. (2009). Although Fukuda et al. (2009) only analyzed $A$. japonica, we assumed that the same temperature and increment relationship can be applied to $A$. anguilla, because of their similar life stages and habitat environment. The estimated number of increments at elapsed days $t$ since release, NI $(t)$, is obtained based on the following equation by Fukuda et al. (2009; Fig. 2).

$$
\begin{gathered}
\text { NI }(t)=\Sigma \text { NIPD }(\mathrm{t}) \\
\text { NIPD }=1 \text { for } T \geq 20^{\circ} \mathrm{C} \\
\text { NIPD }=T \times 0.1-1.0 \text { for } 10<T<20^{\circ} \mathrm{C} \\
\text { NIPD }=0 \text { for } T \leq 10^{\circ} \mathrm{C}
\end{gathered}
$$

where NIPD denotes the number of increments per day, and $T$ is the mean ambient temperature experienced by the particles. Fukuda et al. (2009) showed that NIPD in A. japonica glass eels ceased at temperatures below $10^{\circ} \mathrm{C}$ and regularly deposited 1 ring at temperatures above $20^{\circ} \mathrm{C}$, and we adopted those thresholds. We assumed a direct proportional relationship between NIPD and ambient temperature

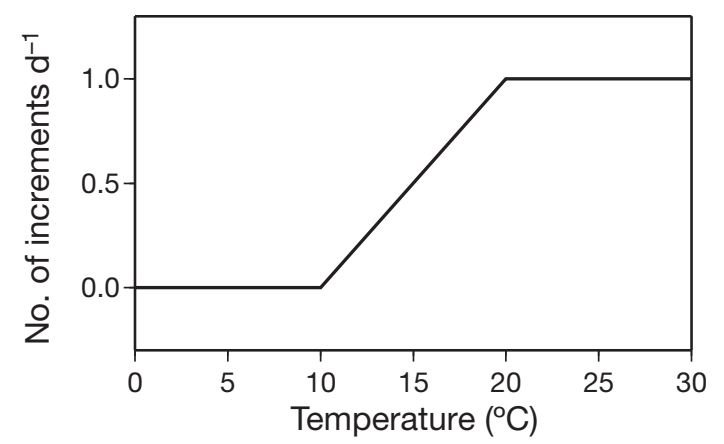

Fig. 2. Relationship between ambient temperature and number of increments formed per day based on Fukuda et al. (2009) 
between 10 and $20^{\circ} \mathrm{C}$ because NIPD was approximately 0.5 (0.43 to 0.48 ) at $15^{\circ} \mathrm{C}$ (Fukuda et al. 2009).

\section{RESULTS}

\section{Latitudinal distribution of particle arrivals}

The results of the Lagrangian simulations for $A n$ guilla anguilla were consistent with observations of larval arrival areas. Within 4 yr of larval drift, $14.6 \%$ of the total particles released arrived at the $20^{\circ} \mathrm{W}$ arrival line. The distribution of particles at $20^{\circ} \mathrm{W}$ was spread from $28.0^{\circ}$ to $60.0^{\circ} \mathrm{N}$, with a peak at $50.0^{\circ} \mathrm{N}$ (Fig. 3). Similar patterns were observed in a previous study using Lagrangian simulations (Kettle \& Haines 2006, Bonhommeau et al. 2009a,b). The countries where active glass eel fisheries take place, such as France, Portugal, Spain, and the UK (Dekker 2000), are located at the latitude where a large number of particles crossed the designated arrival line. Although some particles simulated by Kettle \& Haines (2006) and Bonhommeau et al. (2009a) reached between $0^{\circ}$ and $10^{\circ} \mathrm{N}$, the particles in this study did not reach these latitudes.

In the case of Anguilla japonica, 35.6\% of the total particles arrived at the $30^{\circ} \mathrm{N}$ arrival line within $1 \mathrm{yr}$ in the absence of natural mortality. Particles that passed through the arrival line were transported to the countries where active glass eel fisheries take place, such as Japan and Taiwan (Kim et al. 2007, Zenimoto et al. 2009).

\section{Estimates of larval duration}

To estimate the migration duration of Anguilla anguilla, particle numbers were counted every $10 \mathrm{~d}$ during the drifting period over $4 \mathrm{yr}$. Transport of the fastest particle from the release point to the arrival line took 368 d (Fig. 4a). Particles continued to cross the arrival line for approximately $800 \mathrm{~d}$ at a rate of 0.002 to $1.02 \%$ of the total number of particles arriving every $10 \mathrm{~d}$, with $\geq 1 \% 10 \mathrm{~d}^{-1}$ arriving up to the $4 \mathrm{yr}$ limit (Fig. 4a). The distribution of larval duration varied drastically when mortality was applied. Peaks were detected at 780-800, 660-800, 640-670, 630660 , and $650 \mathrm{~d}$, and the geometric means were 900, $800,710,660$, and $650 \mathrm{~d}$ with mortality rates of 1.0 , 2.0, 3.0, 3.8, and 4.0, respectively (Fig. 4c,e).

In simulations of Anguilla japonica, the minimum duration of migration ranged between 50 and $55 \mathrm{~d}$. Since then, the number of successful particles continued to increase up to approximately $240 \mathrm{~d}$ and then moderately decreased to $360 \mathrm{~d}$ (Fig. 4b). Peaks were
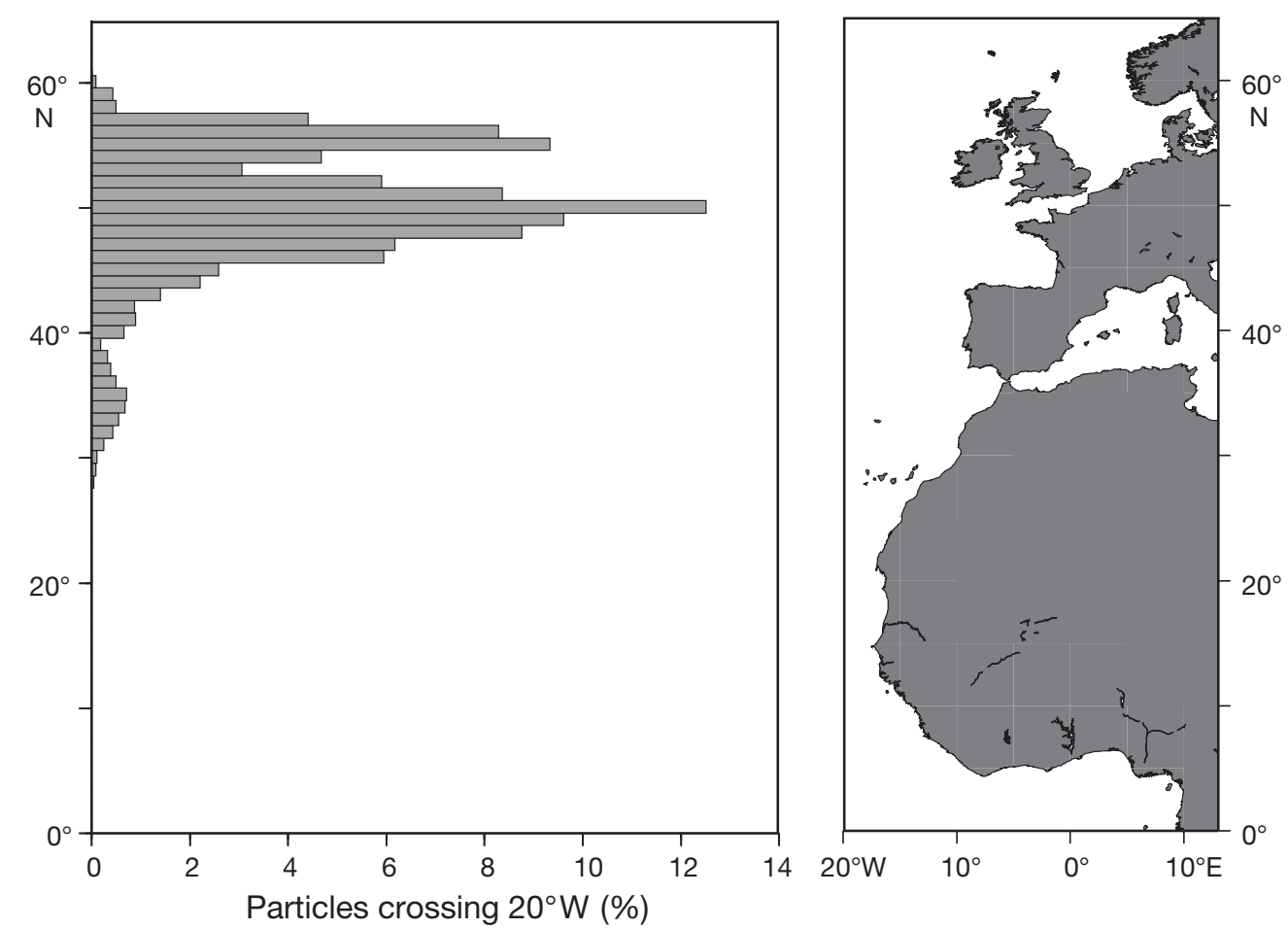

Fig. 3. Anguilla anguilla. Left: Latitudinal distribution of particles from each latitude bin that crossed the $20^{\circ} \mathrm{W}$ line in the Lagrangian simulations for the European eel, plotted alongside the map of the recruitment areas (right) to the east of the arrival line $\left(20^{\circ} \mathrm{W}\right)$. Particles drifted over $4 \mathrm{yr}$ after being released in the spawning area 

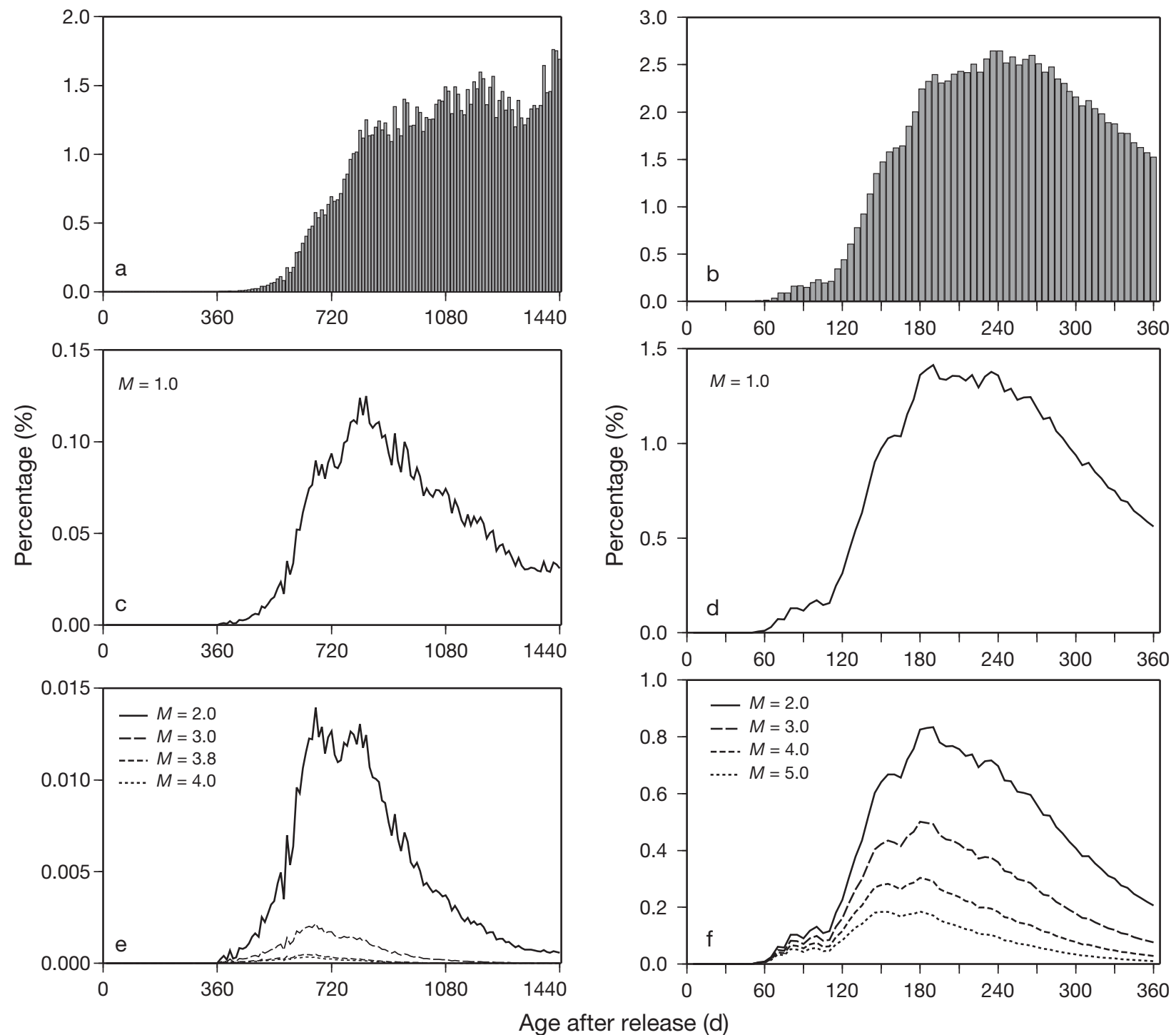

Fig. 4. Anguilla anguilla. (a,b) Time of successful arrivals from release to the 'arrival line' ([a] $\left.20^{\circ} \mathrm{W},[\mathrm{b}] 25^{\circ} \mathrm{N}\right) \mathrm{sampled}$ at 10 $\mathrm{d}$ intervals for the (a) European and (b) Japanese eels. Line plots of the same histogram with annual mortalities $(M)$ of $(\mathrm{c}, \mathrm{d})$ $M=1.0$, (e) $M=2.0-4.0(M=3.8$ was estimated value by Bonhommeau et al. 2009b) and (f) $M=2.0-5.0$

detected at 185-235, 180-205, 180-190, 180-185, and 150-180 d, and the geometric means were 225, 215, 200,190 , and $180 \mathrm{~d}$ when mortality rates of $1.0,2.0$, 3.0, 4.0 and 5.0 were applied, respectively (Fig. 4d,f).

\section{Estimates of ambient temperature and otolith increment counts}

The ambient temperatures to which simulated Anguilla anguilla and A. japonica larvae were exposed were used to estimate the number of otolith increments that would be deposited. In this analysis, we used particles that were within a maximum migration duration of $720 \mathrm{~d}$ ( 2 yr) for A. anguilla and $210 \mathrm{~d}(7 \mathrm{mo})$ for $A$. japonica as long as they experienced a smooth advection pattern, i.e. without any irregular trajectories. Ambient temperature tended to decrease, as the larvae migrated, from 22.4 to $11.0^{\circ} \mathrm{C}$ in the upper layer $(50 \mathrm{~m})$ and from 19.8 to $10.8^{\circ} \mathrm{C}$ in the lower layer $(300 \mathrm{~m})$ of the diurnal migration range for $A$. anguilla (Fig. 5a). Because $A$. anguilla are transported northward by the Gulf Stream, ambient temperature decreased more markedly between 0 and $300 \mathrm{~d}$ than during the later part of the migration (Fig. 5a). In contrast, the mean ambient temperature of $A$. japonica larvae remained steady at above $20^{\circ} \mathrm{C}$ until they reached the Kuroshio 


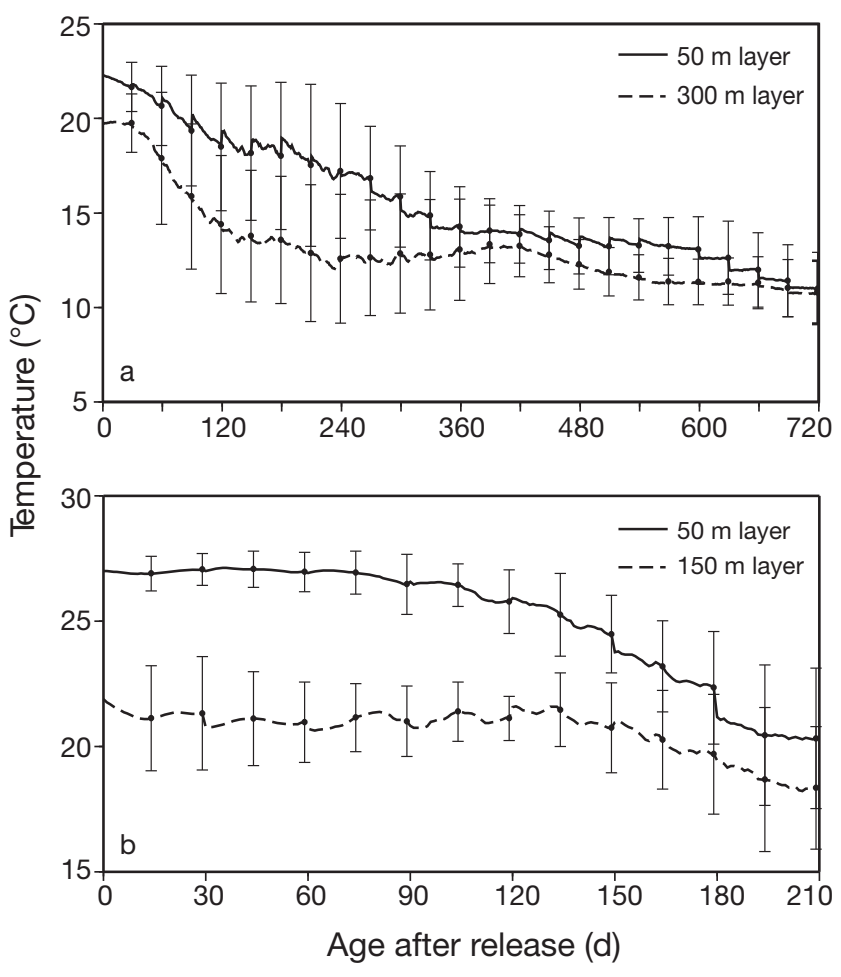

Fig. 5. Anguilla anguilla and A. japonica. Time series of mean ambient temperature $( \pm \mathrm{SD})$ for $(\mathrm{a})$ the European eel and (b) the Japanese eel. Solid and dashed lines: temperature in the uppermost and the lowest layer in diurnal vertical migration, respectively

(about 100 d), which resulted in 1 otolith increment deposition per day, regardless of depth layer. Subsequently, the increment deposition decreased as particles were transported northward by the Kuroshio (Fig. 5b).

The number of visible increments formed during the larval stage was estimated based on the ambient temperature influence above otolith growth. In Anguilla anguilla, the estimated number of increments in $720 \mathrm{~d}$ of migration was 389,233 , and 313 if larvae were continuously transported in the upper layer, lower layer, and when they were allowed to migrate between these layers, respectively (Fig. 6a). In contrast, the number of increments deposited by $A$. japonica was estimated to be $1 \mathrm{~d}^{-1}$ because ambient temperatures largely remained above $20^{\circ} \mathrm{C}$ (Fig. 6b).

\section{DISCUSSION}

We tested whether the larval duration of Anguilla anguilla and $A$. japonica was underestimated by otolith microstructure analysis, based on the demonstrated temperature dependence of otolith growth.

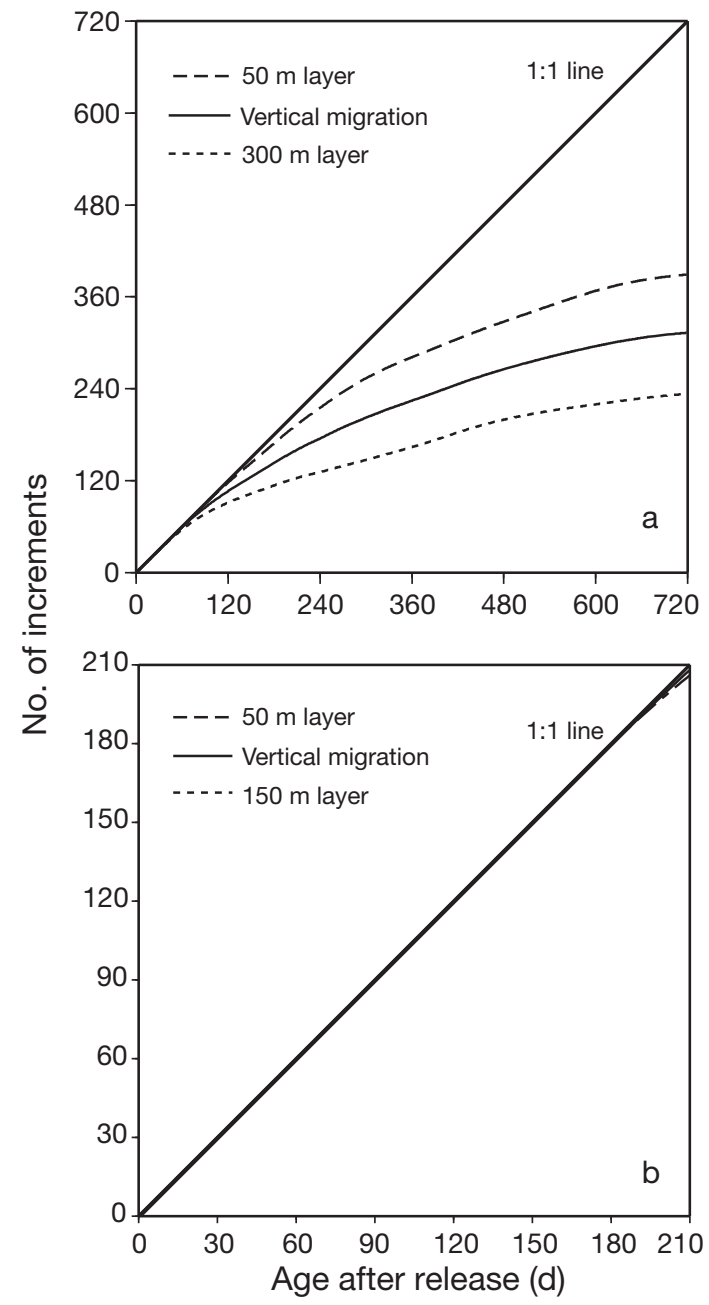

Fig. 6. Anguilla anguilla and A. japonica. Estimated number of deposited increments based on a temperature-dependent equation for (a) the European eel and (b) the Japanese eel

Mean larval duration and experienced ambient temperature were estimated by a Lagrangian numerical simulation of particle transport and model temperature data.

To provide accurate estimates of larval duration in Lagrangian simulations, natural mortality must be accounted for (Cowen et al. 2000, Hare et al. 2002). Without accounting for mortality, the longer the computation period, the more particles will reach the arrival line, which could lead to an incorrect estimate of migration duration. At natural mortality rates of $M=1.0$ to 4.0, the mean larval duration for Anguilla anguilla was estimated to be between 900 and $660 \mathrm{~d}$. In the case of $M=2.0$, the duration ( $800 \mathrm{~d}$ ) was less than in previous studies $(2.4 \mathrm{yr}=864 \mathrm{~d}$; Bonhommeau et al. 2009b). This difference would derive from the different simulation duration employed in each study 
(4 yr in this study, 5 yr in Bonhommeau et al. 2009b). The mean larval duration in Bonhommeau et al. (2009b) would be increased by particles that arrived between 4 and 5 yr.

Peak arrival times differed little between this study and that of Bonhommeau et al. (2009b) (approximately $2.1 \mathrm{yr}=756 \mathrm{~d}$ ). In the case of $M=3.8$, which is the natural mortality estimated by Bonhommeau et al. (2009b), our result (660 d) was markedly higher than theirs. Because no particles reached the arrival line in $4 \mathrm{yr}$ due to high mortality rate at $M=3.8$, the difference was not caused by differences in simulation duration. The difference would be caused by model resolution. The spatial resolution of OFES $\left(1 / 10^{\circ}\right)$ is higher than that of the model used by Bonhommeau et al. (2009b: $\left.1 / 4^{\circ} \times 1 / 3^{\circ}\right)$. Consequently, OFES could describe meso-scale eddies more precisely. Because of entrainment in those eddies, the mean larval duration was prolonged in this study. In contrast, the mean larval duration for Anguilla japonica was estimated to be between 225 and $180 \mathrm{~d}$ with $M=1.0$ to 5.0 .

In otolith microstructure analysis, the larval duration is defined as the period from hatching to recruitment as glass eels in the estuaries. In this study, the duration from the arrival line to estuaries $(>1000 \mathrm{~km}$ for Anguilla anguilla, $1000 \mathrm{~km}$ for A. japonica) should be added to the larval duration. The duration from the arrival line to estuaries was estimated as roughly 3 mo for A. anguilla (Bonhommeau et al. 2009b). For A. japonica, the duration was estimated as approximately $10 \mathrm{~d}$ because larvae metamorphosing into glass eels were transported into the Kuroshio, which has a current speed of $1.5 \mathrm{~m} \mathrm{~s}^{-1}$. Therefore, the calculated mean larval durations were $720 \mathrm{~d}(M=3.8)$ for A. anguilla and $200 \mathrm{~d}(M=4.0)$ for A. japonica. For $A$. anguilla, results based purely on otolith microstructure analysis estimated a relatively short larval duration ( $\leq 1 \mathrm{yr}$; Lecomte-Finiger 1992, Arai et al. 2000, Wang \& Tzeng 2000, Kuroki et al. 2008). On the other hand, cohort analysis and particle-tracking models estimated a longer larval duration (>1.5 yr; Schmidt 1923, Kettle \& Haines 2006, Bonhommeau et al. $2009 b$ ). Our results are in agreement with the longer estimates of larval duration for $A$. anguilla. For $A$. japonica, the larval duration in this study was similar to that based on otolith microstructure analysis (Tsukamoto 1990, Kawakami et al. 1999). Larvae of A. japonica were transported from the spawning area to the arrival line at temperatures $>20^{\circ} \mathrm{C}$ (Fig. 5b). Since 1 increment $d^{-1}$ is formed at these temperatures, the mean larval duration in this study corresponded with that based on otolith microstructure results. Conversely, ambient temperature for $A$. anguilla larvae was $>20^{\circ} \mathrm{C}$ only near the Sargasso Sea and remained $<20^{\circ} \mathrm{C}$ through the migration (Fig. 5a). Minimum larval duration was estimated as 450 to $460 \mathrm{~d}$ (360 to $370 \mathrm{~d}$ to the arrival line and a further $90 \mathrm{~d}$ from the arrival line to the European estuaries). According to the relationship between the number of increments and ambient temperature, the increments deposited during this larval phase were estimated as 256.3 to 259.6 (Fig. 6a). In addition, the increments deposited during the mean larval duration at $M=3.8(720 \mathrm{~d})$ were estimated as 313.2 (Fig. 6a). These estimates agree closely with the minimum and mean number of increments observed by scanning electron microscopy (Arai et al. 2000, Wang \& Tzeng 2000, Kuroki et al. 2008). Our estimates matched the number of increments, but did not agree with the larval migration duration itself. In other words, otolith microstructure analysis did count the number of increments precisely, but their direct interpretation of these counts as larval duration estimates is questionable.

In conclusion, our study generally supported the duration of 2 anguillid species larval migration to be more than 1.5 yr for Anguilla anguilla and about $7 \mathrm{mo}$ for A. japonica. Moreover, estimated increment number based on Lagrangian modeling closely matched the results of otolith observations by microscopy. Thus, we have demonstrated the nature of the gap between actual observation based on otolith microstructure and the actual duration of larval migration. The main cause for the underestimate of larval duration is the slower otolith increment deposition rate at low ambient temperature.

Acknowledgements. The OFES simulation was conducted on the Earth Simulator under the support of the Japan Agency for Marine-Earth Science and Technology (JAMSTEC). We appreciate the valuable comments of 2 anonymous reviewers.

\section{LITERATURE CITED}

Arai T, Otake T, Tsukamoto K (2000) Timing of metamorphosis and larval segregation of the Atlantic eels Anguilla rostrata and Anguilla anguilla, as revealed by otolith microstructure and microchemistry. Mar Biol 137: $39-45$

Bonhommeau S, Chassot E, Rivot E (2008a) Fluctuations in European eel (Anguilla anguilla) recruitment resulting from environmental changes in the Sargasso Sea. Fish Oceanogr 17:32-44

Bonhommeau S, Chassot E, Planque B, Rivot E, Knap AH, Le Pape O (2008b) Impact of climate on eel populations of the Northern Hemisphere. Mar Ecol Prog Ser 373:71-80 
Bonhommeau S, Blanke B, Treguier AM, Grima N and others (2009a) How fast can the European eel (Anguilla anguilla) larvae cross the Atlantic Ocean? Fish Oceanogr 18:371-385

Bonhommeau S, Le Pape O, Gascuel D, Blanke B and others (2009b) Estimates of the mortality and the duration of the trans-Atlantic migration of European eel Anguilla anguilla leptocephali using a particle tracking model. J Fish Biol 74:1891-1914

Bonhommeau S, Castonguay M, Rivot E, Sabatie R, Le Pape O (2010) The duration of migration of Atlantic Anguilla larvae. Fish Fish 11:289-306

Casselman J, Cairns D (2003) Worldwide decline of eel resources necessitates immediate action-Quebec declaration of concern. Fisheries 28:28-30

> Castonguay M, McCleave JD (1987) Vertical distributions, diel and ontogenetic vertical migrations and net avoidance of leptocephali of Anguilla and other common species in the Sargasso Sea. J Plankton Res 9:195-214

Cowen RK, Lwiza KMM, Sponaugle S, Paris CB, Olson DB (2000) Connectivity of marine populations: open or closed? Science 287:857-859

$>$ Dekker W (2000) The fractal geometry of the European eel stock. ICES J Mar Sci 57:109-121

> Dekker W (2003) Did lack of spawners cause the collapse of the European eel, Anguilla anguilla? Fish Manag Ecol 10:365-376

> Doi T, Tozuka T, Yamagata T (2009) Interannual variability of the Guinea Dome and its possible link with the Atlantic Meridional Mode. Clim Dyn 33:985-998

> Feunteun E (2002) Management and restoration of European eel population (Anguilla anguilla): an impossible bargain. Ecol Eng 18:575-591

Friedland KD, Miller MJ, Knights B (2007) Oceanic changes in the Sargasso Sea and declines in recruitment of the European eel. ICES J Mar Sci 64:519-530

Fukuda N, Kuroki M, Shinoda A, Yamada Y, Okamura A, Aoyama J, Tsukamoto K (2009) Influence of water temperature and feeding regime on otolith growth in Anguilla japonica glass eels and elvers: Does otolith growth cease at low temperatures? J Fish Biol 74: 1915-1933

> Hare JA, Churchill JH, Cowen RK, Berger TJ and others (2002) Routes and rates of larval fish transport from the southeast to the northeast United States continental shelf. Limnol Oceanogr 47:1774-1789

> Hurrell JW (1995) Decadal trends in the North Atlantic oscillation-regional temperatures and precipitation. Science 269:676-679

ICES (International Council for the Exploration of the Sea) (2006) Reports of the Eifac/ICES working group on eels, Rome, Italy. ICES CM 2006/ACFM: 16, Ref. DFC, LRC, RMC. ICES, Copenhagen

Itoh S, Yasuda I, Nishikawa H, Sasaki H, Sasai Y (2009) Transport and environmental temperature variability of eggs and larvae of the Japanese anchovy (Engraulis japonicus) and Japanese sardine (Sardinops melanostictus) in the western North Pacific estimated via numerical particle-tracking experiments. Fish Oceanogr 18: 118-133

Kawakami Y, Mochioka N, Nakazono A (1999) Immigration patterns of glass-eels Anguilla japonica entering river in northern Kyushu, Japan. Bull Mar Sci 64:315-327

Kettle AJ, Haines K (2006) How does the European eel (Anguilla anguilla) retain its population structure during its larval migration across the North Atlantic Ocean? Can J Fish Aquat Sci 63:90-106

Kim H, Kimura S, Shinoda A, Kitagawa T, Sasai Y, Sasaki H (2007) Effect of El Niño on migration and larval transport of the Japanese eel (Anguilla japonica). ICES J Mar Sci 64:1387-1395

Kimura S, Tsukamoto K (2006) The salinity front in the North Equatorial Current: a landmark for the spawning migration of the Japanese eel (Anguilla japonica) related to the stock recruitment. Deep Sea Res II 53:315-325

Kimura S, Döös K, Coward AC (1999) Numerical simulation to resolve the issue of downstream migration of the Japanese eel. Mar Ecol Prog Ser 186:303-306

Kitagawa T, Kimura S, Nakata H, Yamada H, Nitta A, Sasai Y, Sasaki H (2009) Immature Pacific bluefin tuna, Thunnus orientalis, utilises cold waters in the Subarctic Frontal Zone for trans-Pacific migration. Environ Biol Fishes 84:193-196

Knights B (2003) A review of the possible impacts of longterm oceanic and climate changes and fishing mortality on recruitment of anguillid eels of the Northern Hemisphere. Sci Total Environ 310:237-244

Kuroki M, Kawai M, Jónsson B, Aoyama J, Miller M, Noakes D, Tsukamoto K (2008) Inshore migration and otolith microstructure/microchemistry of anguillid glass eels recruited to Iceland. Environ Biol Fishes 83:309-325

> Laffaille P, Caraguel JM, Legault A (2007) Temporal patterns in the upstream migration of European glass eels (Anguilla anguilla) at the Couesnon estuarine dam. Estuar Coast Shelf Sci 73:81-90

Lecomte-Finiger R (1992) Growth history and age at recruitment of European glass eels (Anguilla anguilla) as revealed by otolith microstructure. Mar Biol 114:205-210

Mantua NJ, Hare SR, Zhang Y, Wallace JM, Francis RC (1997) A Pacific interdecadal climate oscillation with impacts on salmon production. Bull Am Meteorol Soc 78: 1069-1079

- Masumoto Y (2010) Sharing the results of a high-resolution ocean general circulation model under a multi-discipline framework - a review of OFES activities. Ocean Dyn 60: $633-652$

Masumoto Y, Sasaki H, Kagimoto T, Komori N and others (2004) A fifty-year eddy-resolving simulation of the World Ocean-preliminary outcomes of OFES (OGCM for the earth simulator). J Earth Simulator 1:35-56

> McCleave JD (1993) Physical and behavioural controls on the oceanic distribution and migration of leptocephali. J Fish Biol 43:243-273

McCleave JD (2008) Contrasts between spawning times of Anguilla species estimated from larval sampling at sea and from otolith analysis of recruiting glass eels. Mar Biol 155:249-262

McCleave JD, Kleckner RC (1987) Distribution of leptocephali of the catadromous Anguilla species in the western Sargasso Sea in relation to water circulation and migration. Bull Mar Sci 41:789-806

Miller MJ, Kimura S, Friedland KD, Knights B, Kim H, Jellyman DJ, Tsukamoto K (2009) Review of oceanatmospheric factors in the Atlantic and Pacific Oceans influencing spawning and recruitment of anguillid eels. In: Haro A, Smith KL, Rulifson RA, Moffitt CM and others (eds) Challenges for diadromous fishes in a dynamic global environment. American Fisheries Society, Bethesda, MD, p 231-249

Nakamura M, Kagimoto T (2006) Potential vorticity and 
eddy potential enstrophy in the North Atlantic Ocean simulated by a global eddy-resolving model. Dyn Atmos Oceans 41:28-59

Nonaka M, Nakamura H, Tanimoto Y, Kagimoto T, Sasaki H (2006) Decadal variability in the Kuroshio-Oyashio Extension simulated in an eddy-resolving OGCM. J Clim 19:1970-1989

Otake T, Inagaki T, Hasumoto H, Mochioka N, Tsukamoto K (1998) Diel vertical distribution of Anguilla japonica leptocephali. Ichthyol Res 45:208-211

Sasaki H, Nonaka M, Masumoto Y, Sasai Y, Uehara H, Sakuma H (2008) An eddy-resolving hindcast simulation of the quasiglobal ocean from 1950 to 2003 on the Earth Simulator. In: Hamilton K, Ohfuchi W (eds) High resolution numerical modelling of the atmosphere and ocean. Springer, New York, NY, p 157-185

Schmidt J (1923) Breeding places and migrations of the eel. Nature 111:51-54

Tabeta O, Tanaka K, Yamada J, Tzeng WN (1987) Aspects of the early life-history of the Japanese eel Anguilla japonica determined from otolith microstructure. Bull Jpn Soc Sci Fish 53:1727-1734

Editorial responsibility: Alejandro Gallego, Aberdeen, UK
Taguchi B, Xie SP, Schneider N, Nonaka M, Sasaki H, Sasai Y (2007) Decadal variability of the Kuroshio Extension: observations and an eddy-resolving model hindcast. J Clim 20:2357-2377

Tatsukawa K (2003) Eel resources in Asia. In: Aida K, Tsukamoto K, Yamauchi K (eds) Eel biology. Springer-Verlag, Tokyo, p 255-274

Tsukamoto K (1990) Recruitment mechanism of the eel, Anguilla japonica, to the Japanese coast. J Fish Biol 36: 659-671

Tsukamoto K (2006) Spawning of eels near a seamount. Nature 439:929

Wang CH, Tzeng WN (2000) The timing of metamorphosis and growth rates of American and European eel leptocephali: a mechanism of larval segregative migration. Fish Res 46:191-205

Zenimoto K, Kitagawa T, Miyazaki S, Sasai Y, Sasaki H, Kimura S (2009) The effects of seasonal and interannual variability of oceanic structure in the western Pacific North Equatorial current on larval transport of the Japanese eel Anguilla japonica. J Fish Biol 74: 1878-1890

Submitted: November 15, 2010; Accepted: June 15, 2011 Proofs received from author(s): September 16, 2011 